\title{
Low testosterone predicts hypoxemic respiratory insufficiency and mortality in patients with COVID-19 disease: another piece in the COVID puzzle
}

\author{
W. Vena ${ }^{1} \cdot$ A. Pizzocaro ${ }^{1} \cdot$ G. Maida ${ }^{1} \cdot$ M. Amer ${ }^{1} \cdot$ A. Voza ${ }^{2} \cdot$ A. Di Pasquale $^{3} \cdot$ F. Reggiani ${ }^{4} \cdot$ M. Ciccarelli $^{3} \cdot$ C. Fedeli $^{2}$. \\ D. Santi ${ }^{5}$ - E. Lavezzi ${ }^{6,1}$ - A. G. Lania ${ }^{6,1}$ (D) . G. Mazziotti ${ }^{6,1} \cdot$ Humanitas COVID19 Task Force
}

Received: 9 August 2021 / Accepted: 1 November 2021 / Published online: 18 November 2021

(C) Italian Society of Endocrinology (SIE) 2021

\begin{abstract}
Purpose Hypogonadism was described in high number of male subjects with severe acute respiratory syndrome coronavirus 2 (SARS-CoV-2) infection. In this study, we investigated whether low testosterone $(T)$ values may influence the clinical presentation and outcome of SARS-CoV-2-related pneumonia in a large population of adult males with coronavirus disease 19 (COVID-19).

Methods Two hundred twenty one adult males hospitalized for COVID-19 at the IRCCS Humanitas Research Hospital, Rozzano-Milan (Italy) were consecutively evaluated for arterial partial pressure oxygen $\left(\mathrm{PaO}_{2}\right) /$ fraction of inspired oxygen $\left(\mathrm{FiO}_{2}\right)$ ratio, serum $\mathrm{T}$ and inflammatory parameters at study entry, need of ventilation during hospital stay and in-hospital mortality.

Results Subjects low $T$ values ( $<8 \mathrm{nmol} / \mathrm{L} ; 176$ cases) were significantly older $(P=0.001)$ and had higher serum interleukin-6 $(P=0.001)$, C-reactive protein $(P<0.001)$, lactate dehydrogenase $(P<0.001)$, ferritin $(P=0.012)$, lower $P / F$ ratio $(P=0.001)$, increased prevalence of low T3 syndrome $(P=0.041)$, acute respiratory insufficiency $(P<0.001)$, more frequently need of ventilation $(P<0.001)$ and higher mortality rate $(P=0.009)$ compared to subjects with higher $\mathrm{T}$ values. In the multivariable regression analyses, $T$ values maintained significant associations with acute respiratory insufficiency (odds ratio [OR] $0.85,95 \%$ confidence interval [CI] 0.79-0.94; $P<0.001$ and in-hospital mortality (OR 0.80, 95\% CI 0.69-0.95; $P=0.009$ ), independently of age, comorbidities, thyroid function and inflammation.

Conclusion Low T levels values are associated with unfavorable outcome of COVID-19. Prospective studies are needed to evaluate the long-term outcomes of hypogonadism related to COVID-19 and the clinical impact of T replacement during and after acute illness.
\end{abstract}

Keywords Testosterone $\cdot$ SARS-CoV-2 infection $\cdot$ Hypogonadism $\cdot$ COVID-19 $\cdot$ Pneumonia $\cdot$ Mortality

W. Vena and A. Pizzocaro contributed equally to the study.

A. G. Lania

andrea.lania@hunimed.eu

1 Endocrinology, Diabetology and Medical Andrology Unit, IRCCS Humanitas Research Hospital, via Manzoni 56, Rozzano, 20089 Milan, Italy

2 Emergency Unit, IRCCS Humanitas Research Hospital, via Manzoni 56, Rozzano, 20089 Milan, Italy

3 Pneumology Unit, IRCCS Humanitas Research Hospital, via Manzoni 56, Rozzano, 20089 Milan, Italy
4 Nephrology Unit, IRCCS Humanitas Research Hospital, via Manzoni 56, Rozzano, 20089 Milan, Italy

5 Unit of Endocrinology, Department of Biomedical, Metabolic and Neural Sciences, University of Modena and Reggio Emilia, Modena, Italy

6 Department of Biomedical Sciences, Humanitas University, via Rita Levi Montalcini 4, Pieve Emanuele, 20090 Milan, Italy 


\section{Introduction}

Since December 2019, severe acute respiratory syndrome coronavirus 2 (SARS-CoV-2) infection has become a worldwide urgent public health concern with more than 170 million of infected subjects. Despite the terrible burden of health-related consequences, including now up to 3.5 million deaths worldwide, unfortunately the majority of biological mechanisms involved in the severe acute respiratory SARS-CoV-2 infection and related COVID-19 disease, still remain unknown [1] . There is convincing evidence that males may have more severe COVID-19 with higher risk of mortality as compared to females [2-4]. The determinants of such a gender-related variability in clinical outcome of COVID-19 are still unclear, with some authors suggesting low disease awareness and high comorbidity burden as possible determinants of more aggressive COVID-19 in males [5]. Previous studies reported low testosterone (T) serum levels in a large number of males with COVID-19 [6-11]. However, clinical impact of T serum levels on SARS-CoV-2 infection outcomes is still unclear. In particular, it is unknown whether the clinical relevance of low T values in COVID19 may resemble that described in other acute and severe diseases [12-14]. Conversely, clinical and experimental evidence suggests role of high $\mathrm{T}$ values as a possible risk factor for severe COVID-19 disease trough complex androgen receptor (AR)-mediated mechanisms [15-17].

In this monocentric study, we focused on possible impact of low $\mathrm{T}$ serum levels on clinical presentation and outcome of SARS-CoV-2-related pneumonia.

\section{Materials and methods}

This is a monocentric study performed on 221 consecutive male patients hospitalized for COVID-19 at the IRCCS Humanitas Research Hospital, Rozzano-Milan, Italy between November 1, 2020 and January 31, 2021. The inclusion criteria were: (1) hospitalization for COVID-19 diagnosed by real-time reverse-transcriptase-polymerasechain-reaction assay of nasal and pharyngeal swab specimens and or bronco-alveolar lavage fluid associated with clinical and radiological signs of pneumonia [18]; (2) male sex; (3) older than 18 years; (4) completed hospital course at study end (discharged or dead). Requirement of intubation and mechanical respiratory support at study entry was an exclusion criterion.

Testosterone was measured using Access Testosterone assay (Beckman Coulter Inc, Fullerton, CA), a competitive immunoassay method that has analytical and clinical acceptable correlation with mass-spectrometry method [19]. Other parameters were measured using standardized methods. According to total T serum levels, patients were categorized in three groups: Group I $(T<8 \mathrm{nmol} / \mathrm{L})$, Group II ( $T$ between 8 and $12 \mathrm{nmol} / \mathrm{L})$, Group III $(T>12$ $\mathrm{nmol} / \mathrm{L}$ ). Patients of Group I were defined hypogonadal [20] and they were further subdivided in two categories according to serum luteinizing hormone $(\mathrm{LH})$ values $(\mathrm{LH}$ $<9.4 \mathrm{U} / \mathrm{L}, \mathrm{LH} \geq 9.4 \mathrm{U} / \mathrm{L})[20,21]$.

The first endpoint of the study was the association between serum $\mathrm{T}$ levels and respiratory insufficiency at study entry. The diagnostic criteria for acute hypoxemic respiratory failure were $\mathrm{PaO}_{2}<60 \mathrm{mmHg}$ on room air or arterial partial pressure oxygen $\left(\mathrm{PaO}_{2}\right)$ /fraction of inspired oxygen $\left(\mathrm{FiO}_{2}\right)$ ratio $<300 \mathrm{mmHg}$ on oxygen, as measured by arterial blood gas analysis [22]. Secondary endpoints were the associations between serum $\mathrm{T}$ and (1) inflammatory markers, (2) comorbidities, (3) need of ventilation during hospital stay and (4) in-hospital mortality rate. Moreover, in 194 subjects, we evaluated the association between serum $T$ values and thyroid function/dysfunction potentially related to COVID-19 [23, 24].

At study entry, before starting any treatment for COVID19, enrolled subjects were evaluated for: $\mathrm{PaO}_{2} / \mathrm{FiO}_{2}$ ratio, hypertension, coronary artery diseases (CAD), chronic kidney disease (CKD) (from stage $3 \mathrm{~A}$ and worse, corresponding to eGFR $<60 \mathrm{~mL} / \mathrm{min} / 1.73 \mathrm{~m}^{2}$, calculated by CKD-EPI), obesity (defined as a Body Mass Index $>30 \mathrm{~kg} / \mathrm{m}^{2}$ ), past or active cancer, chronic obstructive pulmonary disease (COPD), serum T (nmol/L), LH (U/L), 25-hydroxyvitamin vitamin $\mathrm{D}(25 \mathrm{OHD})(\mathrm{ng} / \mathrm{mL})$, thyroid-stimulating hormone (TSH) $(\mu \mathrm{UI} / \mathrm{mL})$, free-triiodothyronine (fT3) (pmol/L), freetetraiodothyronine (fT4) (pmol/L), interleukin-6 (IL-6, pg/ $\mathrm{mL})$, lactate dehydrogenase (LDH) (U/L), ferritin $(\mathrm{ng} / \mathrm{mL})$, C-reactive protein $(\mathrm{CRP})(\mathrm{mg} / \mathrm{dL})$.

According to the Guidelines of the Italian Society of Infectious Disease [25] and to the Institutional internal protocol, patients with COVID-19 at the admission started standard therapy consisting of enoxaparin at either prophylactic or therapeutic doses according to the clinical judgment [26], antiviral agents (lopinavir/ritonavir, remdesivir), corticosteroids and antibiotics.

Some of the enrolled patients had been already involved in other COVID-19 studies evaluating endpoints which were different from the present study [26-31].

The study was approved by the Ethics Committee of IRCCS Humanitas Research Hospital and the patients gave their consent to use the clinical and biochemical data for research purposes. 


\section{Statistical analysis}

Data were presented as median and absolute range, unless otherwise stated. Since most of variables were non-normally distributed as assessed by Kolmogorov-Smirnov test, non-parametric tests were used. The comparisons were performed by Mann-Whitney and Kruskal-Wallis tests, with post hoc Bonferroni's correction when appropriate. Frequencies were compared by the Chi-Squared test, with Fisher's correction when appropriate. A logistic regression analysis was performed and the odds ratio (OR) with $95 \%$ confidence interval (95\% C.I.) were calculated to evaluate the determinants of acute hypoxemic respiratory failure at study entry and in-hospital mortality. All risk factors with a $P$ value under 0.10 were then submitted to multivariable logistic regression analyses taking into account the minimal guidance criterion of ten events per variable [32]. $P$ value $<0.05$ was considered as significant.

\section{Results}

Two hundred twenty one adult subjects were included in the study, with median age of 70.5 years (range 26-93 years) and median body mass index (BMI) of $27.2 \mathrm{~kg} / \mathrm{m}^{2}$ (range 17.9-45.0). Study participants characteristics are summarized in Table 1.

Normal T serum levels (Group III) were found in only $7.7 \%$ of the study population $(n=17)$, whereas frankly low $\mathrm{T}$ levels were detected in 176 patients $(79.6 \%$, Group I) and borderline T serum levels in 28 (12.7\%, Group II). Subjects included in Group I were significantly older $(P=0.001)$ and

Table 1 Demographical and clinical characteristics of study population, considering the entire cohort and the stratification for total testosterone serum levels

\begin{tabular}{|c|c|c|c|c|c|}
\hline & \multirow[t]{2}{*}{ Entire population } & \multicolumn{4}{|c|}{ Subgroups by serum total testosterone values } \\
\hline & & $\begin{array}{l}\text { Group I } \\
T<8 \mathrm{nmol} / \mathrm{L}\end{array}$ & $\begin{array}{l}\text { Group II } \\
T 8-12 \mathrm{nmol} / \mathrm{L}\end{array}$ & $\begin{array}{l}\text { Group III } \\
T>12 \mathrm{nmol} / \mathrm{L}\end{array}$ & $P$ values \\
\hline$N$ & 221 & 176 & 28 & 17 & \\
\hline Age (years) & $70.5(26-93)$ & $72.5(30-93)$ & $63(45-86)$ & $59(26-84)$ & 0.001 \\
\hline $\mathrm{BMI}\left(\mathrm{kg} / \mathrm{m}^{2}\right)$ & $27.2(17.9-45.0)$ & $27.0(17.9-42.3)$ & $27.6(18.0-35.6)$ & $27.0(22.2-45.0)$ & 0.798 \\
\hline Arterial hypertension no. (\%) & $109(60.9)$ & $87(61.7)$ & $13(52.0)$ & $9(69.2)$ & 0.536 \\
\hline Diabetes mellitus no. (\%) & $53(24.0)$ & $45(25.6)$ & $5(17.9)$ & $3(17.6)$ & 0.551 \\
\hline CAD no. $(\%)$ & $95(43.0)$ & $78(44.3)$ & $8(28.6)$ & $9(52.9)$ & 0.203 \\
\hline Active or past cancer no. (\%) & $51(23.1)$ & $45(25.6)$ & $3(10.7)$ & $3(17.6)$ & 0.191 \\
\hline COPD no. $(\%)$ & $37(16.7)$ & $32(18.2)$ & $3(10.7)$ & $2(11.8)$ & 0.524 \\
\hline CKD no. $(\%)$ & $30(13.6)$ & $24(13.6)$ & $3(10.7)$ & $3(17.6)$ & 0.804 \\
\hline$\geq 2$ comorbidities no. $(\%)$ & $122(55.2)$ & $104(59.1)$ & $8(28.6) *$ & $10(58.8)^{*}$ & 0.001 \\
\hline IL-6 (pg/mL) & $26.0(2.0-480.0)$ & $32.5(2.0-480.0)$ & $14.0(2.0-182.0) *$ & $14.0(4.0-119.0)^{*}$ & 0.001 \\
\hline Ferritin $(\mathrm{ng} / \mathrm{mL})$ & $572.2(3.8-5027.0)$ & $606.8(3.8-5027.0)$ & $533.7(37.0-2013.0)^{\S}$ & $237.8(47.0-918.0)^{*}$ & 0.012 \\
\hline $\mathrm{CRP}(\mathrm{mg} / \mathrm{dL})$ & $8.7(0.1-80.6)$ & $9.8(0.1-56.6)$ & $6.3(0.6-80.6)^{\S}$ & $1.70(0.1-14.6)^{*}$ & $<0.001$ \\
\hline LDH (U/L) & $314.0(31.0-2484.0)$ & $331.5(79.0-2484.0)$ & $268.0(184.0-456.0)^{*, \S}$ & $207.0(31.0-572.0)^{*}$ & $<0.001$ \\
\hline LH (U/L) & $7.2(0.2-78.0)$ & $7.1(0.2-45.3)$ & $7.5(3.5-78.0)$ & $7.23(3.5-14.1)$ & 0.507 \\
\hline $25(\mathrm{OH}) \mathrm{D}(\mathrm{ng} / \mathrm{mL})$ & $15.0(2.0-73.0)$ & $15.0(2.0-73)$ & $19.0(4.0-47.0)$ & $15.5(6.3-31.0)$ & 0.425 \\
\hline $\mathrm{TSH}(\mathrm{uUI} / \mathrm{mL}) * *$ & $0.66(0.0-93.0)$ & $0.64(0.0-93.0)$ & $0.66(0.1-2.6)$ & $1.35(0.3-5.1)$ & 0.206 \\
\hline $\mathrm{fT} 3(\mathrm{pmol} / \mathrm{L}) * *$ & $3.43(1.3-6.3)$ & $3.32(1.3-6.3)$ & $3.59(2.3-6.3)$ & $3.86(2.6-4.8)^{*}$ & 0.041 \\
\hline Low-T3-syndrome, $n(\%)^{* *}$ & $94(48.5)$ & $80(53.3)$ & $9(33.3)$ & $5(29.4)$ & 0.041 \\
\hline $\mathrm{fT} 4(\mathrm{pmol} / \mathrm{L}) * *$ & $13.39(7.6-25.9)$ & $13.98(7.6-25.9)$ & $14.06(9.2-21.5)$ & $12.8(8.1-19.8)$ & 0.410 \\
\hline $\mathrm{PaO}_{2} / \mathrm{FiO}_{2}$ no. $(\%)$ & $295.0(97.0-592.0)$ & $278.1(97.0-592.0)$ & $310.5(117.0-471.0)^{*}$ & $328.0(247.0-452.0)^{*}$ & 0.001 \\
\hline
\end{tabular}

Values in bold were statistically significant

$B M I$ body mass index, $C A D$ coronary artery disease, $C K D$ chronic kidney disease, $C O P D$ chronic obstructive pulmonary disease, $C R P$ C-reactive protein, $f T 3$ free-triiodothyronine, $f T 4$ free-tetraiodothyronine, $I L-6$ interleukin-6, $L D H$ lactate dehydrogenase, $L H$ luteinizing hormone, $\mathrm{PaO}_{2} / \mathrm{FiO}_{2}$ arterial partial pressure oxygen/fraction of inspired oxygen ratio, $\mathrm{T}$ total testosterone, $\mathrm{TSH}$ thyroid-stimulating hormone, $25(\mathrm{OH}) \mathrm{D}$ 25 hydroxyvitamin D

Categorical data are presented as $n / n$ or $\%$, whereas continuous data are presented as median and range

${ }^{\S} P<0.05$ vs Group III

${ }^{*} P<0.05$ vs Group I

***Available for 194 subjects 
had higher number of comorbidities $(P=0.001)$, serum IL-6 levels $(P=0.001), \mathrm{CRP}(P<0.001)$, ferritin $(P=0.012)$ and LDH $(P<0.001)$ compared to Group III (Table 1). Moreover, Group I showed lower $\mathrm{PaO}_{2} / \mathrm{FiO}_{2}$ ratio $(P=0.001)$ and fT3 serum levels $(P=0.041)$ as compared to subjects with normal T values of Group III (Table 1). Subjects of Group II had significantly lower IL-6 $(P=0.001), \mathrm{LDH}(P=0.018)$ and higher $\mathrm{PaO}_{2} / \mathrm{FiO}_{2}$ ratio $(P=0.044)$ compared to Group I, without significant differences in CRP $(P=0.107)$ and ferritin $(P=0.869)$ values (Table 1$)$. Moreover, subjects of Group II had significantly higher serum CRP $(P=0.005)$, LDH $(P=0.04)$ and ferritin $(P=0.009)$ compared to Group III, without significant difference in $\mathrm{PaO} 2 / \mathrm{FiO} 2$ ratio $(P=0.128)$ (Table 1).

When subjects included in Group I were stratified according to $\mathrm{LH}$ serum levels, men with $\mathrm{LH}<9.4 \mathrm{U} / \mathrm{L}$ were significantly younger $(P<0.001)$ and had lower prevalence of $C A D$ $(P=0.008)$, COPD $(P<0.005)$ and lower comorbidities burden $(P=0.015)$ as compared to subjects with $\mathrm{LH} \geq 9.4 \mathrm{U} / \mathrm{L}$, without significant differences in BMI, arterial hypertension, diabetes mellitus, cancer, CKD, inflammatory parameters and T levels (Supplemental Table 1).

TSH and fT4 serum levels did not differ among groups (Table 1). However, a significant difference in fT3 serum levels was detected among groups $(P=0.041)$ (Table 1$)$. The low T3 syndrome could be defined as the condition in which reduced fT3 serum levels were detected together with normal TSH and fT4 serum levels [33]. The non-thyroidal illness was found in up to $48.5 \%$ (94/194) of study subjects, with significantly higher prevalence in Group I as compared to Group II and III (53.3\% vs $33.3 \%$ vs $29.4 \%$, respectively, $P=0.041)$ (Table 1).

\section{Respiratory outcomes}

At study entry, 115 subjects (52.0\%) fulfilled criteria for acute hypoxemic respiratory failure in association with higher ferritin $(P=0.003)$ and lower $\mathrm{T}$ values $(P<0.001)$ (Table 2). These associations remained statistically significant in the multivariable analysis (Fig. 1). The prevalence of acute hypoxemic respiratory failure was significantly higher in subjects of Group I as compared to both Group II $(P=0.009)$ and Group III $(P<0.001)$, without significant difference between Group II and III ( $P=0.488)$ (Fig. 2).

No significant difference in acute hypoxemic respiratory failure was observed in hypogonadal subjects with $\mathrm{LH}<9.4$ $\mathrm{U} / \mathrm{L}$ compared to those with $\mathrm{LH} \geq 9.4 \mathrm{U} / \mathrm{L}$ (Supplemental Table 1).

During hospital stay, 134 subjects $(60.6 \%)$ required oxygen support (99 with high-flow nasal or mask oxygen; 33 with continuous positive airways pressure [CPAP] and two with invasive ventilation). The prevalence of patients requiring ventilation (either invasive or non-invasive) was
Table 2 Determinants of hypoxemic respiratory failure at admission, in 221 males hospitalized for COVID-19

\begin{tabular}{lllr}
\hline & \multicolumn{3}{l}{ Univariate analysis } \\
\cline { 2 - 4 } & OR & $95 \%$ CI & $P$ values \\
\hline Age & 1.01 & $0.99-1.03$ & 0.579 \\
BMI & 1.04 & $0.97-1.11$ & 0.314 \\
Arterial hypertension & 1.09 & $0.64-1.89$ & 0.741 \\
Diabetes mellitus & 1.73 & $0.92-3.26$ & 0.089 \\
CAD & 0.78 & 0.46 .1 .32 & 0.351 \\
Active or past cancer & 0.86 & $0.46-1.59$ & 0.620 \\
COPD & 1.44 & $0.70-2.94$ & 0.323 \\
CKD & 0.57 & $0.26-1.25$ & 0.159 \\
$\geq 2$ comorbidities & 1.20 & $0.71-2.05$ & 0.496 \\
IL-6 (tertiles) & 0.91 & $0.65-1.26$ & 0.553 \\
Ferritin (tertiles) & 1.67 & $1.19-2.34$ & $\mathbf{0 . 0 0 3}$ \\
CRP & 1.02 & $0.99-1.05$ & 0.278 \\
LDH & 1.00 & $1.00-1.01$ & 0.144 \\
fT3 & 1.01 & $0.95-1.07$ & 0.608 \\
LH & 0.99 & $0.97-1.03$ & 0.970 \\
T & 0,85 & $0.79-0.94$ & $<\mathbf{0 . 0 1}$ \\
\hline
\end{tabular}

Values in bold were statistically significant

$B M I$ body mass index, $C A D$ coronary artery disease, $C K D$ chronic kidney disease, $C O P D$ chronic obstructive pulmonary disease, $C R P$ C-reactive protein, $f T 3$ free-triiodothyronine, $I L-6$ interleukin-6, $L D H$ lactate dehydrogenase, $L H$ luteinizing hormone, $f T 3$ free $\mathrm{T}$, total testosterone

significantly higher in Group I compared to either Group II or III ( $P<0.001$ for both comparisons), whereas no significant difference was observed between the latter two groups $(P=0.756)$ (Fig. 2).

\section{In-hospital mortality}

The overall in-hospital mortality rate was $17.6 \%(n=39)$. All but one subjects deceased during hospitalization were included in Group I $(P<0.009$ vs Group II and III). In univariable regression model, in-hospital mortality was associated with older age $(P<0.001)$, BMI $(P=0.003)$, $\mathrm{PaO}_{2} / \mathrm{FiO}_{2}$ ratio $(P=0.010)$, CAD $(P=0.002)$, cancer $(P=0.017)$, COPD $(P=0.001)$, serum CRP $(P=0.039)$, IL-6 $(P<0.001)$, LDH $(P=0.044), \mathrm{T}(P<0.001)$ and fT3 values $(P<0.001)$ (Table 3$)$. In multivariable regression analyses, low $\mathrm{T}$ serum levels maintained the statistically significant association with in-hospital mortality independently of age, comorbidities, inflammation markers, fT3 values and BMI (Fig. 3A-C).

In Group I, in-hospital mortality rate was significantly higher in subjects with $\mathrm{LH} \geq 9.4 \mathrm{U} / \mathrm{L}$ vs. those with lower LH serum values (Supplemental Table 1). 

analysis evaluating the determinants of hypoxemic respiratory insufficiency at admission, in male subjects hospitalized for COVID-19. The bold values were statistically significant
Fig.1 Multivariable regression
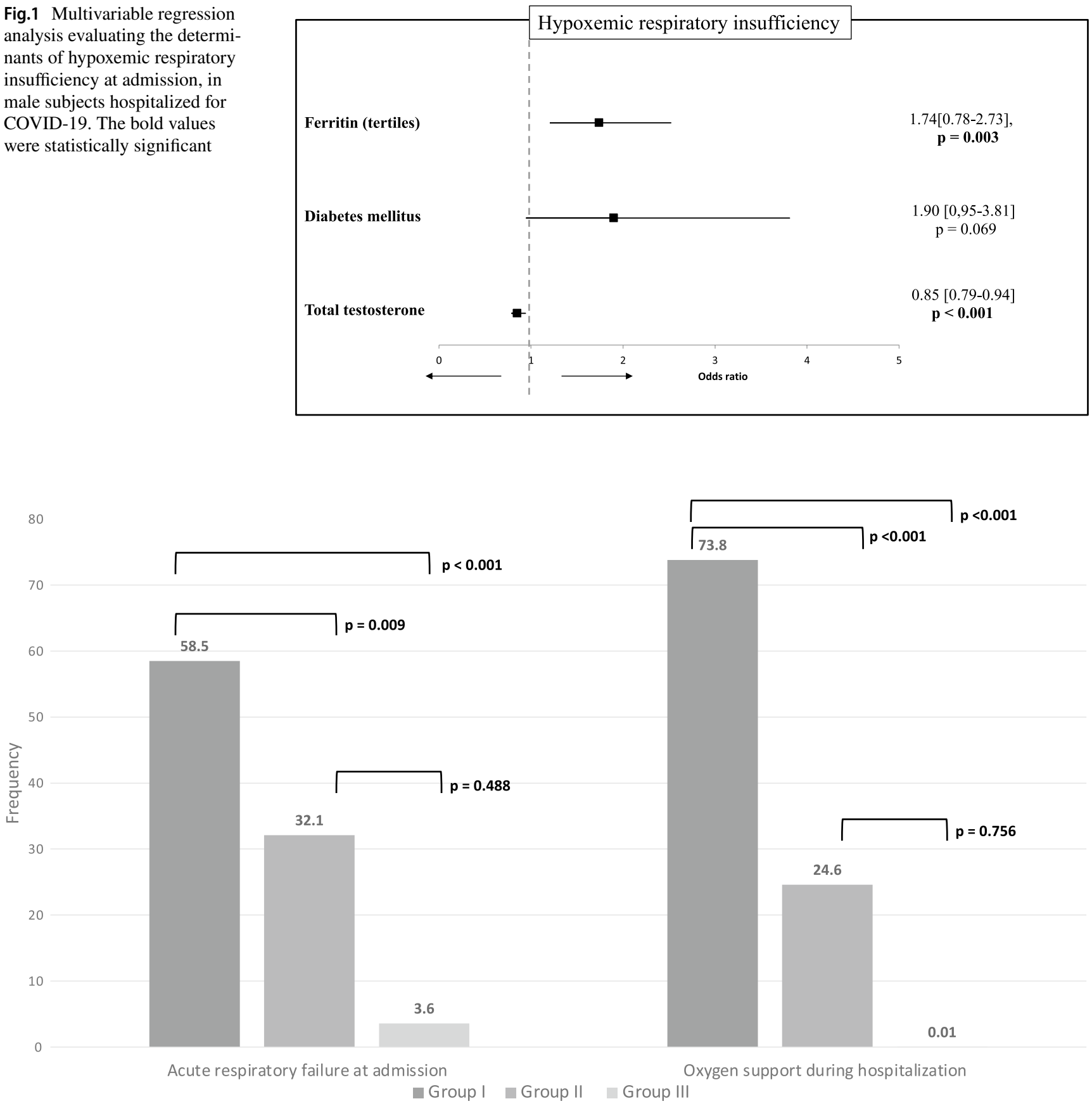

Fig. 2 Frequencies of acute respiratory failure at admission and oxygen support during hospitalization in 221 male subjects with COVID19 stratified in three groups according to serum total testosterone

(T) values (Group I, $<T<8 \mathrm{nmol} / \mathrm{L}$; Group II, $T$ between 8 and 12 nmol/L; Group III, $T>12 \mathrm{nmol} / \mathrm{L}$ ). The comparisons were performed by Chi-square tests, with Fisher correction when appropriate

\section{Discussion}

This study reports an association between T deficiency and high risk of acute hypoxemic respiratory failure at admission, need of oxygen support and mortality during hospital stay in adult males with COVID-19, independently of age, inflammatory markers, low T3 syndrome and comorbidity burden.

Advanced age and comorbidities are unequivocally associated with faster $\mathrm{T}$ decline in men [34-36]. It is largely demonstrated that acute and critical illnesses cause a $\mathrm{T}$ decrease due to the direct action of cytokines on Leydig 
Table 3 Determinants of in-hospital mortality in 221 male subjects hospitalized for COVID-19

\begin{tabular}{lllr}
\hline & \multicolumn{2}{l}{ Univariate analysis } \\
\cline { 2 - 4 } & OR & $95 \%$ CI & $P$ values \\
\hline Age & 1.08 & $1.03-1.11$ & $<\mathbf{0 . 0 0 1}$ \\
BMI & 0.84 & $0.75-0.94$ & $\mathbf{0 . 0 0 3}$ \\
Arterial hypertension & 1.46 & $0.69-3.07$ & 0.320 \\
Diabetes mellitus & 1.27 & $0.58-2.78$ & 0.550 \\
CAD & 3.24 & $1.56-6.72$ & $\mathbf{0 . 0 2 0}$ \\
Active or past cancer & 2.47 & $1.17-5.18$ & $\mathbf{0 . 0 1 7}$ \\
COPD & 3.77 & $1.72-8.29$ & $\mathbf{0 . 0 0 1}$ \\
CKD & 1.83 & $0.75-4.49$ & 0.186 \\
$\geq 2$ comorbidities & 9.36 & $3.19-27.44$ & $<\mathbf{0 . 0 0 1}$ \\
IL-6 (tertiles) & 2.52 & $1.51-4.21$ & $<\mathbf{0 . 0 0 1}$ \\
Ferritin (tertiles) & 0.95 & $0.62-1.45$ & 0.827 \\
$\mathrm{CRP}$ & 1.03 & $1.01-1.06$ & $\mathbf{0 . 0 3 9}$ \\
$\mathrm{LDH}^{2}$ & 1.01 & $1.00-1.02$ & $\mathbf{0 . 0 4 4}$ \\
$\mathrm{LH}_{\mathrm{T}}$ & 1.02 & $0.99-1.05$ & 0.286 \\
$\mathrm{fT}$ & 0.75 & $0.64-0.87$ & $<\mathbf{0 . 0 0 1}$ \\
$\mathrm{PaO}_{2}$ /FiO & & $0,12-0,48$ & $<\mathbf{0 . 0 0 1}$ \\
\hline
\end{tabular}

Values in bold were statistically significant

$B M I$ body mass index, $C A D$ coronary artery disease, $C K D$ chronic kidney disease, $C O P D$ chronic obstructive pulmonary disease, $C R P$ C-reactive protein, $f T 3$ free-triiodothyronine, $I L-6$ interleukin-6, $L D H$ lactate dehydrogenase, $\mathrm{LH}$ luteinizing hormone, $\mathrm{PaO}_{2} / \mathrm{FiO}_{2}$ arterial partial pressure oxygen/fraction of inspired oxygen ratio, $T$ total testosterone

cells during the acute phase [37], as well as a reduction of LH secretion by the pituitary during the chronic phase [38]. Large epidemiologic studies report hypogonadism prevalence from 9 to $17 \%$ in elderly population $[35,36]$, with increased prevalence up to $50 \%$ in hospitalized elderly subjects (mean age 86 years); moreover, an inverse correlation between serum $\mathrm{T}$ levels and mortality was reported [14]. Interestingly, Iglesias et al. reported respiratory tract infection as the main cause of hospitalization in hypogonadal men [14]. However, a correlation between hypogonadism and susceptibility to infections is not yet clear. Indeed, T acts as a modulator of immune response [39, 40], but, at the same time, one could argue that the inflammation could be itself the cause of $\mathrm{T}$ secretion reduction. In attempt to explain the higher COVID-19 mortality rates observed in the male population, the possible role of $\mathrm{T}$ during the disease course has been largely debated [41], but only few studies have properly investigated its role in the clinical setting.

First, a significant association between low $\mathrm{T}$ and both inflammation parameters and COVID-19 disease course severity was described by few studies so far. Rastrelli et al. reported for the first time the increase of inflammatory markers (IL-6, CRP, PCT, LDH and white blood cells) in a small groups of subjects with lower T (i.e., $\mathrm{T}<5.0 \mathrm{nmol} / \mathrm{L}$ ) admitted to intensive care units (ICU) due to COVID-19 pneumonia as compared to those with higher $\mathrm{T}$ serum levels at time of admission [6]. Similar findings have been later confirmed in larger cohorts of COVID-19 affected subjects, either asymptomatic or admitted to internal medicine wards and ICU [7-10]. These studies are poorly comparable, due to the different thresholds applied to identify low T subjects and the heterogeneity of the populations involved (e.g., ICU vs asymptomatic subjects). The high prevalence observed in our cohort suggests a specific association between SARSCoV-2 infection and gonadal failure, possibly involving the whole hypothalamic-pituitary-gonadal (HPG) axis, in association with a higher degree of systemic inflammation, as similarly described for other endocrine glands [28, 42].

The prevalence of hypogonadism is increased within specific populations, including patients with diabetes, metabolic syndrome, obesity, cardiovascular disease, COPD, renal disease and cancer [43]. Consistently, a high burden of comorbidities was observed in our low $\mathrm{T}$ population, with more than $50 \%$ of subjects with low $T$ values having 2 or more comorbidities. Moreover, up to $50 \%$ of the population was found to have low T3 syndrome, which is an established predictor of higher mortality among COVID-19 hospitalized subjects [23, 24]. However, when the potential clinical impact of low $\mathrm{T}$ values was evaluated, we found that low $\mathrm{T}$ serum levels were associated with unfavorable COVID-19 outcomes, independently of comorbidities burden, thyroid status and inflammation markers. This finding fosters the hypothesis that low $T$ values should be considered as a direct consequence of COVID-19 disease rather than an epiphenomenon of systemic illness or inflammation.

High rates of acute respiratory insufficiency were reported among low T populations with COVID-19 disease, ranging from 62.5 to $100 \%$ of individuals, and worse respiratory outcomes have been found in the hypogonadal groups as compared to normal T subjects by some $[6,7,9,11]$, but not all authors [8]. We found a significant difference in acute respiratory insufficiency prevalence between low $\mathrm{T}$ and normal subjects. A multivariable logistic regression analysis allowed us to confirm the direct relationship between $\mathrm{T}$ levels and respiratory insufficiency at admission, independently from other confounding factors. A higher risk of hospitalization for respiratory cause has been previously reported among hypogonadal subjects [14]. This could be directly due to the role of hypoxemia and hypercapnia, rather than inflammatory state itself, reducing serum $\mathrm{T}$, as described in adult COPD subjects [44]. Nevertheless, the exact mechanism of such association remains unclear.

Mortality rates, similarly to respiratory outcomes, appear to be quite variable across the COVID-19 hypogonadal populations, ranging from 5 to $27 \%$ [7, 9]. This variability likely reflects the highly heterogeneous study populations. Among 
Fig. 3 Multivariable regression analyses evaluating the determinants of in-hospital mortality in male subjects hospitalized for COVID-19. The three analyses $(3 \mathrm{~A}, \mathrm{~B}, \mathrm{C})$ were performed taking into account the minimal guidance criterion of ten events per variable [32]. The bold values were statistically significant. $B M I$ body mass index, $C A D$ coronary artery disease, $C O P D$ chronic obstructive pulmonary disease, $f T 3$ free-triiodothyronine, $I L-6$ interleukin 6, $L D H$ lactate dehydrogenase

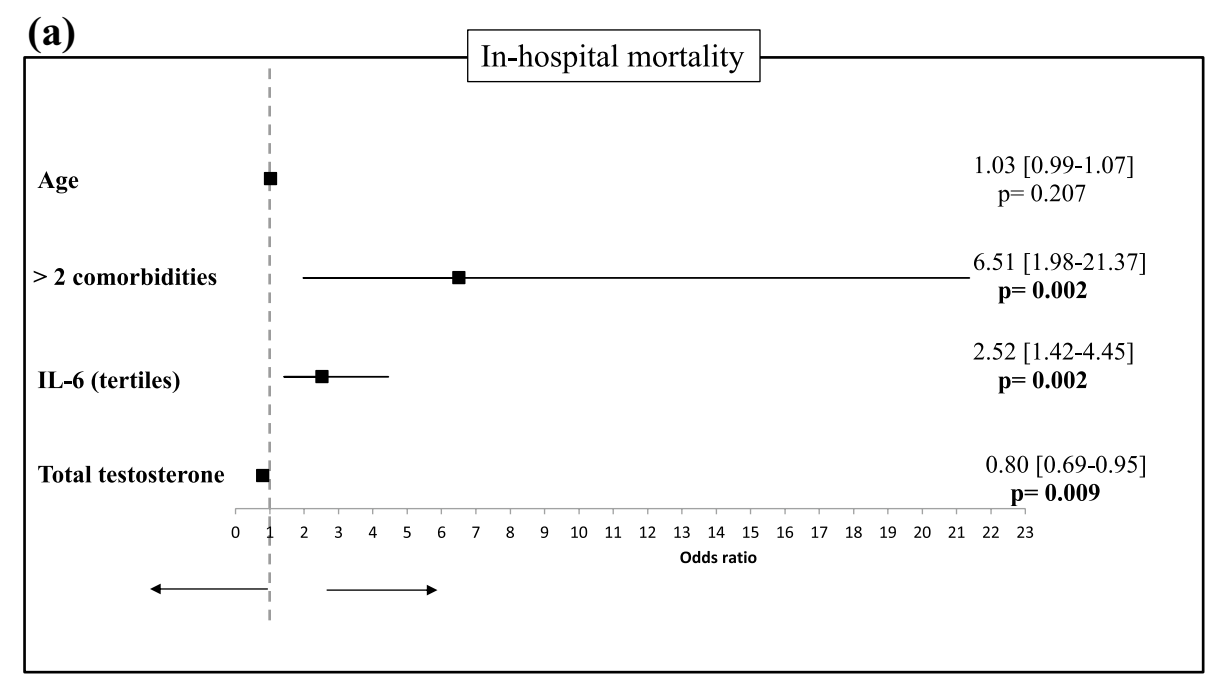

(b)

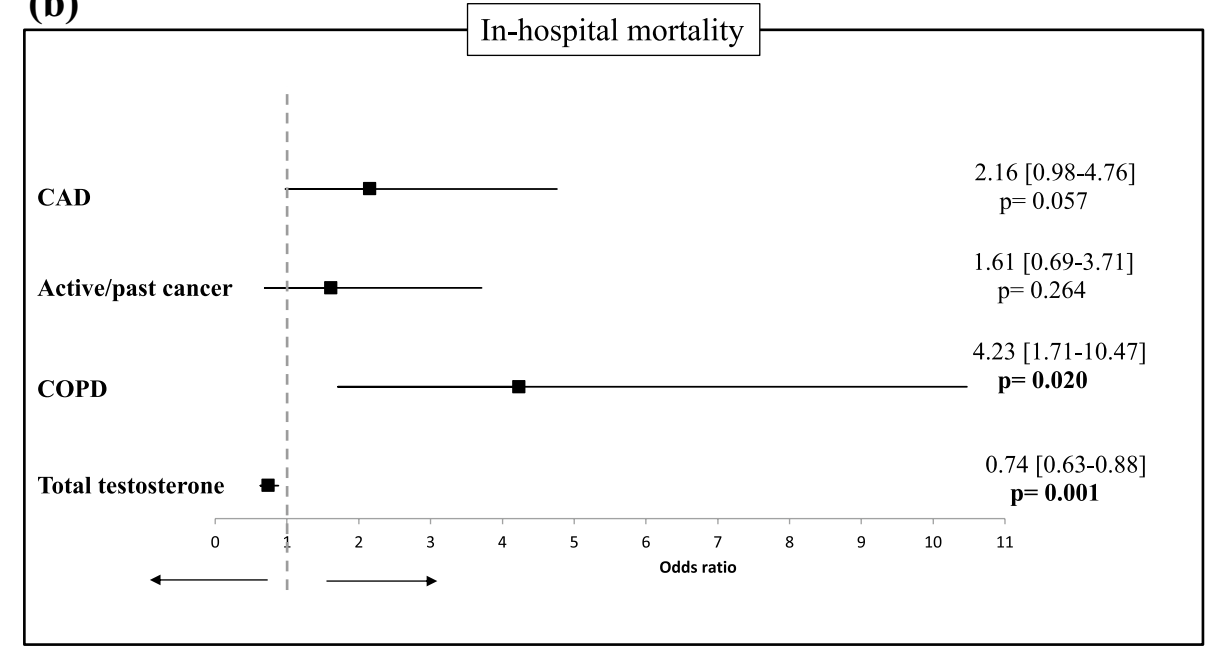

(c)

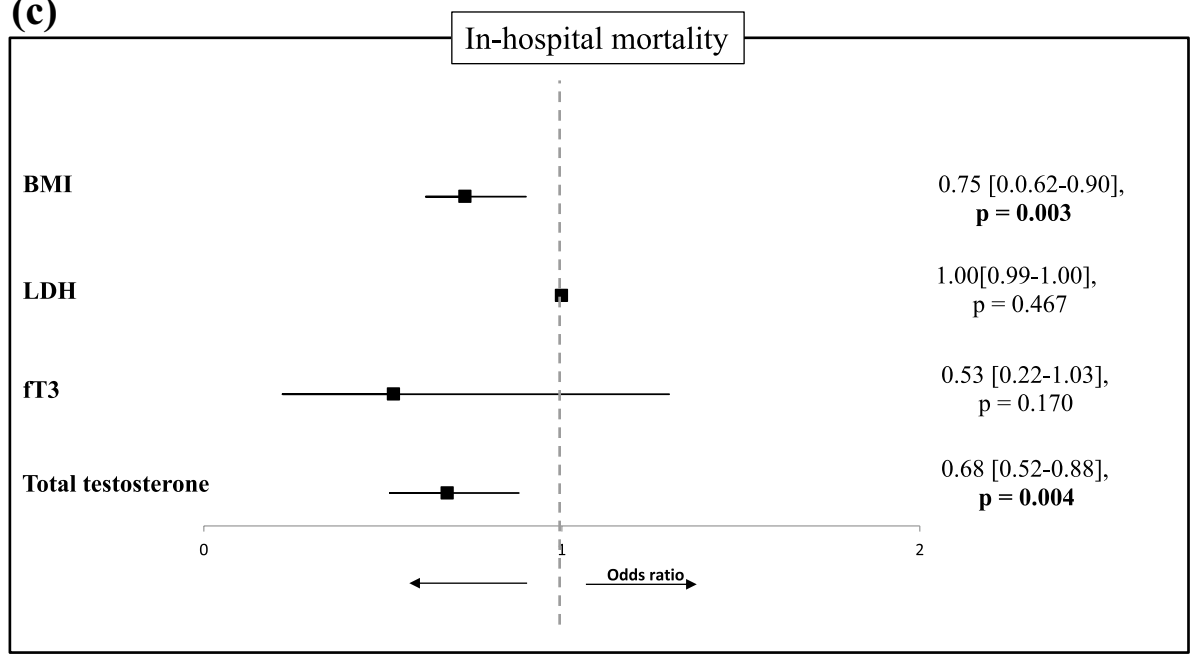

these, indeed, some studies reported an increased mortality rate across low $\mathrm{T}$ subjects $[7,9,10]$, whereas others could not describe a similar association $[6,8]$. In our population, overall mortality was as high as $17.6 \%$, confirming results obtained from a recent meta-analysis involving hospitalized subjects with COVID-19 [45]. Interestingly, in our large and homogeneous population of elderly adults with mild to moderate conditions at hospital admission, we could describe 
for the first time among low $\mathrm{T}$ subjects both an increased serum level of inflammatory markers and a significantly higher risk of acute hypoxemic respiratory failure and mortality (Fig. 3). Thus, we could speculate that low T serum levels could be the result of a higher degree of inflammation and systemic allostatic mechanisms, as confirmed by significantly lower fT3 serum levels observed in Group I subjects. However, multivariable regression analyses showed the independent relation between inflammatory markers, age and comorbidities and the main study outcomes. These observations suggest a direct relationship between low $\mathrm{T}$ levels and unfavorable disease course, possibly related to the known immuno-modulatory action of testosterone [39, 40], consistently with previous evidence demonstrating higher respiratory disease-related mortality in hypogonadal subjects $[46,47]$.

Due to the frequent association of primary hypogonadism with other conditions (e.g., Klinefelter syndrome), the extent to which different forms of hypogonadism influence mortality remain largely disputed. Interestingly, in line with observations made by Araujo et al. [46], our cohort showed a significantly higher mortality rate in subjects with primary hypogonadism, independently from $\mathrm{T}$ levels. However, we recognize that age and comorbidities, are also significantly higher in the primary hypogonadism group as compared to central forms.

Lastly, some authors suggest a possible relationship between higher $T$ values and worse COVID-19 disease mediated by AR. Indeed, the transmembrane protease serine 2 receptor (TMPRSS2) expression, essential for viral entrance in human cells, appears to be increased by the AR activation, ultimately favoring viral entrance [16]. Consistently, men receiving androgen-deprivation therapy seem to be at lower risk of infection [15], although the causal nature of this association has not been established. Unfortunately, none of our study subjects either was receiving androgen deprivation therapy or had increased serum $\mathrm{T}$ levels, therefore, we could not draw any conclusion on this issue.

This study has some limitations. First, the advanced patients' age suggests late-onset hypogonadism may have been the main possible cause of low T levels. Indeed, we did not provide information about previous gonadal status of enrolled subjects and testosterone values were measured in a single blood sample drawn at study entry, to rule out possible interferences induced by treatments of COVID19 used during hospital stay. This approach, did not allow also to perform a correct diagnosis of hypogonadism in all subjects as well as to define the duration of exposure to low testosterone values. Indeed, according to reference guidelines [21], diagnosis of hypogonadism should be based on morning (08.00-10.00 a.m.) T levels below the reference range in at least two different occasions; in our study, a single measure of $\mathrm{T}$ was made at hospital admission, probably over-estimating the prevalence of hypogonadism. Moreover, circadian rhythms of $\mathrm{T}$ secretion have not been respected in $\mathrm{T}$ determination [48]. Again, we could not assess serum sex-hormone-binding globulin (SHBG) levels, that may have provided more reliable information on peripheral hormone status. Nonetheless, SHBG determination is particularly useful when borderline T levels are detected. However, the majority of the study population resulted to have frankly low $\mathrm{T}$ levels. Moreover, although elevated SHBG levels have been reported in many pathological conditions $[49,50]$, the only study measuring SHBG during COVID-19 could not find differences across study subjects stratified for disease severity [6]. Finally, our study did not include a control group which may have allowed to clarify whether hypogonadism was a specific consequence of SARS-CoV-2 infection. However, the end-point of this study was the impact of hypogonadism on clinical outcome of COVID-19 rather than clarifying the determinants of hypogonadism in this clinical setting.

Notwithstanding these limitations, our results may have a relevant clinical impact. Indeed, long-term sequelae of COVID-19 are increasingly being appreciated on physical [51] and psychological [52] health. Fatigue, muscular weakness, mood swings and sleep disturbances have been reported as part of the so-called "post-acute COVID syndrome" and are all common symptoms among hypogonadal patients [53]. Consistent with the robust evidence linking T secretion impairment during acute COVID-19, one could speculate that the impairment of HPG axis could persist over time, invalidating a prompt physical and psychological recovery, especially for patients with pre-existent frailty.

\section{Conclusion}

This retrospective cohort adds consistent evidence to previous reports about the role of low circulating $\mathrm{T}$ levels as a marker of higher risk of severe outcomes among COVID19 male patients. In view of the pandemic dimensions of COVID-19, prospective studies are needed to evaluate gonadal function in subjects recovering from illness and its relationship with long-term consequences of the disease on general health status.

Supplementary Information The online version contains supplementary material available at https://doi.org/10.1007/s40618-021-01700-7.

\section{Declarations}

Conflict of interest Walter Vena received a project grant from IBSA. All other authors declare they do not have conflict of interest that is relevant to the subject matter or materials included in this work. Gherardo Mazziotti is a member of Editorial Board of the Journal of Endocrinological Investigation. 
Ethical approval All the procedures performed in the study were in accordance with the ethical standards of the Ethics Committee of IRCCS Humanitas Research Hospital, Rozzano-Milan, Italy, and with the 1964 Helsinki Declaration and its later amendments or comparable ethical standards.

Informed consent Informed consent was obtained from all the individual partecipants included in the study.

\section{References}

1. Datta SD, Talwar A, Lee JT (2020) A proposed framework and timeline of the spectrum of disease due to SARS-CoV-2 infection: illness beyond acute infection and public health implications. JAMA 324(22):2251-2252

2. Booth A, Reed AB, Ponzo S, Yassaee A, Aral M, Plans D et al (2021) Population risk factors for severe disease and mortality in COVID-19: a global systematic review and meta-analysis. PLoS ONE 16(3):e0247461

3. Phelan AL, Katz R, Gostin LO (2020) The novel coronavirus originating in Wuhan, China: challenges for global health governance. JAMA 323(8):709-710

4. Huang C, Wang Y, Li X, Ren L, Zhao J, Hu Y et al (2020) Clinical features of patients infected with 2019 novel coronavirus in Wuhan, China. Lancet 395(10223):497-506

5. The Lancet (2020) The gendered dimensions of COVID-19. Lancet 395(10231): 1168

6. Rastrelli G, Di Stasi V, Inglese F, Beccaria M, Garuti M, Di Costanzo D et al (2021) Low testosterone levels predict clinical adverse outcomes in SARS-CoV-2 pneumonia patients. Andrology 9(1):88-98

7. Dhindsa S, Zhang N, McPhaul MJ, Wu Z, Ghoshal AK, Erlich EC et al (2021) Association of circulating sex hormones with inflammation and disease severity in patients with COVID-19. JAMA Netw Open 4(5):e2111398

8. Camici M, Zuppi P, Lorenzini P, Scarnecchia L, Pinnetti C, Cicalini $S$ et al (2021) The role of testosterone in SARS-CoV-2 infection: a key pathogenic factor and a biomarker for severe pneumonia. Int J Infect Dis 108:244-251

9. Çayan S, Uğuz M, Saylam B, Akbay E (2020) Effect of serum total testosterone and its relationship with other laboratory parameters on the prognosis of coronavirus disease 2019 (COVID-19) in SARS-CoV-2 infected male patients: a cohort study. Aging Male 23(5):1493-1503

10. Salonia A, Pontillo M, Capogrosso P, Gregori S, Tassara M, Boeri L et al (2021) Severely low testosterone in males with COVID-19: a case-control study. Andrology 9(4):1043-1052

11. Cinislioglu AE, Cinislioglu N, Demirdogen SO, Sam E, Akkas F, Altay MS et al (2021) The relationship of serum testosterone levels with the clinical course and prognosis of COVID-19 disease in male patients: a prospective study. Andrology 19. https://doi. org/10.1111/andr.13081

12. Nakashima A, Ohkido I, Yokoyama K, Mafune A, Urashima M, Yokoo T (2017) Associations between low serum testosterone and all-cause mortality and infection-related hospitalization in male hemodialysis patients: a prospective cohort study. Kidney Int Rep 2(6): 1160-1168

13. Zurfluh S, Nickler M, Ottiger M, Steuer C, Kutz A, Christ-Crain $\mathrm{M}$ et al (2018) Dihydrotestosterone is a predictor for mortality in males with community-acquired pneumonia: results of a 6-year follow-up study. Respir Res 19(1):240

14. Iglesias P, Prado F, Macías MC, Guerrero MT, Muñoz A, Ridruejo $\mathrm{E}$ et al (2014) Hypogonadism in aged hospitalized male patients: prevalence and clinical outcome. J Endocrinol Invest 37(2):135-141

15. Montopoli M, Zumerle S, Vettor R, Rugge M, Zorzi M, Catapano CV et al (2020) Androgen-deprivation therapies for prostate cancer and risk of infection by SARS-CoV-2: a populationbased study ( $\mathrm{N}=4532)$. Ann Oncol 31(8):1040-1045

16. Samuel RM, Majd H, Richter MN, Ghazizadeh Z, Zekavat SM, Navickas A et al (2020) Androgen signaling regulates SARSCoV-2 receptor levels and is associated with severe COVID-19 symptoms in men. Cell Stem Cell 27(6):876-89.e12

17. Younis JS, Skorecki K, Abassi Z (2021) The double edge sword of testosterone's role in the COVID-19 pandemic. Front Endocrinol (Lausanne). 12:607179

18. Guan WJ, Ni ZY, Hu Y, Liang WH, Ou CQ, He JX et al (2020) Clinical characteristics of coronavirus disease 2019 in China. N Engl J Med 382(18):1708-1720

19. Dittadi R, Matteucci M, Meneghetti E, Ndreu R (2018) Reassessment of the access testosterone chemiluminescence assay and comparison with LC-MS method. J Clin Lab Anal 32(3):3

20. Corona G, Goulis DG, Huhtaniemi I, Zitzmann M, Toppari J, Forti G et al (2020) European Academy of Andrology (EAA) guidelines on investigation, treatment and monitoring of functional hypogonadism in males: endorsing organization: European Society of Endocrinology. Andrology 8(5):970-987

21. Bhasin S, Brito JP, Cunningham GR, Hayes FJ, Hodis HN, Matsumoto AM et al (2018) Testosterone therapy in men with hypogonadism: an endocrine society clinical practice guideline. J Clin Endocrinol Metab 103(5):1715-1744

22. Ware LB, Matthay MA (2000) The acute respiratory distress syndrome. N Engl J Med 342(18):1334-1349

23. Lui DTW, Lee CH, Chow WS, Lee ACH, Tam AR, Fong CHY et al (2021) Thyroid dysfunction in relation to immune profile, disease status, and outcome in 191 patients with COVID-19. J Clin Endocrinol Metab 106(2):e926-e935

24. Schwarz Y, Percik R, Oberman B, Yaffe D, Zimlichman E, Tirosh A (2021) Sick euthyroid syndrome on presentation of patients with COVID-19: a potential marker for disease severity. Endocr Pract 27(2):101-109

25. Lombardy Section Italian Society I, Tropical D (2020) Vademecum for the treatment of people with COVID-19. Edition 2.0, 13 March 2020. Le Infezioni Med. 28(2):143-152

26. Lodigiani C, Iapichino G, Carenzo L, Cecconi M, Ferrazzi P, Sebastian $\mathrm{T}$ et al (2020) Venous and arterial thromboembolic complications in COVID-19 patients admitted to an academic hospital in Milan, Italy. Thrombosis Res 191:9-14

27. Ellinghaus D, Degenhardt F, Bujanda L, Buti M, Albillos A, Invernizzi P et al (2020) Genomewide association study of severe Covid-19 with respiratory failure. N Engl J Med 383(16):1522-1534

28. Lania A, Sandri MT, Cellini M, Mirani M, Lavezzi E, Mazziotti G (2020) Thyrotoxicosis in patients with COVID-19: the THYRCOV study. Eur J Endocrinol 183(4):381-387

29. Mirani M, Favacchio G, Carrone F, Betella N, Biamonte E, Morenghi $E$ et al (2020) Impact of comorbidities and glycemia at admission and dipeptidyl peptidase 4 inhibitors in patients with type 2 diabetes with COVID-19: a case series from an academic hospital in Lombardy, Italy. Diabetes Care 43(12):3042-3049

30. Bifulco M, Ciccarelli M, Bruzzese D, Dipasquale A, Lania AG, Mazziotti G et al (2021) The benefit of statins in SARS-CoV-2 patients: further metabolic and prospective clinical studies are needed. Endocrine 71(2):270-272

31. Mazziotti G, Lavezzi E, Brunetti A, Mirani M, Favacchio G, Pizzocaro A et al (2021) Vitamin D deficiency, secondary hyperparathyroidism and respiratory insufficiency in hospitalized patients with COVID-19. J Endocrinol Invest 44(10):2285-2293 
32. Pavlou M, Ambler G, Seaman SR, Guttmann O, Elliott P, King M et al (2015) How to develop a more accurate risk prediction model when there are few events. BMJ Br Med J. 351:h3868

33. Fliers E, Boelen A (2021) An update on non-thyroidal illness syndrome. J Endocrinol Invest 44(8):1597-1607

34. Salonia A, Rastrelli G, Hackett G, Seminara SB, Huhtaniemi IT, Rey RA et al (2019) Paediatric and adult-onset male hypogonadism. Nat Rev Dis Primers 5(1):38

35. Wu FC, Tajar A, Beynon JM, Pye SR, Silman AJ, Finn JD et al (2010) Identification of late-onset hypogonadism in middle-aged and elderly men. N Engl J Med 363(2):123-135

36. Araujo AB, O'Donnell AB, Brambilla DJ, Simpson WB, Longcope C, Matsumoto AM et al (2004) Prevalence and incidence of androgen deficiency in middle-aged and older men: estimates from the Massachusetts Male Aging Study. J Clin Endocrinol Metab 89(12):5920-5926

37. Guo H, Calkins JH, Sigel MM, Lin T (1990) Interleukin-2 is a potent inhibitor of Leydig cell steroidogenesis. Endocrinology 127(3):1234-1239

38. Vanhorebeek I, Langouche L, Van den Berghe G (2006) Endocrine aspects of acute and prolonged critical illness. Nat Clin Pract Endocrinol Metab 2(1):20-31

39. Vom Steeg LG, Dhakal S, Woldetsadik YA, Park HS, Mulka KR, Reilly EC et al (2020) Androgen receptor signaling in the lungs mitigates inflammation and improves the outcome of influenza in mice. PLoS Pathog 16(7):e1008506

40. Corsini E, Galbiati V, Papale A, Kummer E, Pinto A, Serafini MM et al (2016) Role of androgens in dhea-induced rack1 expression and cytokine modulation in monocytes. Immun Ageing 13:20

41. Auerbach JM, Khera M (2021) Testosterone's role in COVID-19. J Sex Med 18(5):843-848

42. Pizzocaro A, Colombo P, Vena W, Ariano S, Magnoni P, Reggiani F et al (2021) Outcome of Sars-COV-2-related thyrotoxicosis in survivors of Covid-19: a prospective study. Endocrine 73(2):255-260

43. Zarotsky V, Huang MY, Carman W, Morgentaler A, Singhal PK, Coffin D et al (2014) Systematic literature review of the risk factors, comorbidities, and consequences of hypogonadism in men. Andrology 2(6):819-834
44. Karadag F, Ozcan H, Karul AB, Yilmaz M, Cildag O (2009) Sex hormone alterations and systemic inflammation in chronic obstructive pulmonary disease. Int J Clin Pract 63(2):275-281

45. Corona G, Pizzocaro A, Vena W, Rastrelli G, Semeraro F, Isidori AM et al (2021) Diabetes is most important cause for mortality in COVID-19 hospitalized patients: systematic review and metaanalysis. Rev Endocr Metab Disord 22(2):275-296

46. Araujo AB, Kupelian V, Page ST, Handelsman DJ, Bremner WJ, McKinlay JB (2007) Sex steroids and all-cause and cause-specific mortality in men. Arch Intern Med 167(12):1252-1260

47. Laughlin GA, Barrett-Connor E, Bergstrom J (2008) Low serum testosterone and mortality in older men. J Clin Endocrinol Metab 93(1):68-75

48. Bremner WJ, Vitiello MV, Prinz PN (1983) Loss of circadian rhythmicity in blood testosterone levels with aging in normal men. J Clin Endocrinol Metab 56(6):1278-1281

49. Scheingraber S, Dobbert D, Schmiedel P, Seliger E, Dralle H (2005) Gender-specific differences in sex hormones and cytokines in patients undergoing major abdominal surgery. Surg Today 35(10):846-854

50. Basualto-Alarcón C, Llanos P, García-Rivas G, Troncoso MF, Lagos D, Barrientos G et al (2021) Classic and novel sex hormone binding globulin effects on the cardiovascular system in men. Int J Endocrinol 2021:5527973

51. Nalbandian A, Sehgal K, Gupta A, Madhavan MV, McGroder C, Stevens JS et al (2021) Post-acute COVID-19 syndrome. Nat Med 27(4):601-615

52. Tarsitani L, Vassalini P, Koukopoulos A, Borrazzo C, Alessi F, Di Nicolantonio C et al (2021) Post-traumatic stress disorder among COVID-19 survivors at 3-month follow-up after hospital discharge. J Gen Intern Med 36(6):1702-1707

53. Ramakrishnan RK, Kashour T, Hamid Q, Halwani R, Tleyjeh IM (2021) Unraveling the mystery surrounding post-acute sequelae of COVID-19. Front Immunol 12:686029

Publisher's Note Springer Nature remains neutral with regard to jurisdictional claims in published maps and institutional affiliations. 